\title{
Effect of Anti-Zona Antibodies in Follicular Fluid and Serum on ICSI Outcomes For Explained and Unexplained Groups
}

\author{
Dr. Saba Sabeeh H. Al-Ubodi \\ (M.B.Ch. B., Urology and Infertility Department/ Thi-Qar College of Medicine) \\ Dr. Sahib Yahiya Hassan Al-Murshidi \\ (Assistant professor, Urology and Infertility Department/ College of Medicine/ Kufa \\ University)

\section{Dr. Bassima Shamkhi Al- Gazzali} \\ Assistant professor, Gynecology and Obstetrical Department/ College of Medicine/ Kufa \\ University)
}

\begin{abstract}
:
Objective: This study aims to determine the presence of blood serum and follicular antizona pellucid antibody in two groups of sub-fertile women (explained and unexplained), to evaluate the influence of these autoantibodies on ICSI treatment outcomes and to interpret these findings according to the cause of subfertility treatment outcome.
\end{abstract}

Methods and Materials: This prospective cohort study included 45 sub-fertile women who are divided into subgroups; that are the explained and unexplained groups. All females underwent 45 IVF-ICSI cycles after a certain ovarian stimulation protocol, 45 reached the egg retrieval stage and 44 was reaching embryo transfer stage, at the Fertility center in AL-Najaf Al-Ashraf city from October 2015 to November 2016. Women had undergone thorough assessments (clinical history and full examination) and frequent ultrasonography with basal hormonal level in cycle day two and hematological assessment for AZA, hormonal assessments (E2), two days before retrieval. Also on the day of oocyte retrieval, follicular fluid was centrifuged and freeze for assessing AZA later. After 2 weeks, serum assessed for HCG to detect biochemical pregnancy.

Results: The study found that the age mean and range of the studied groups were $(29.71 \pm 6.62)(18-45 y e a r)$; the BMI mean was $(27.70 \pm 4.05) \mathrm{Kg} / \mathrm{m}^{2}$, ranged between $(19$ -

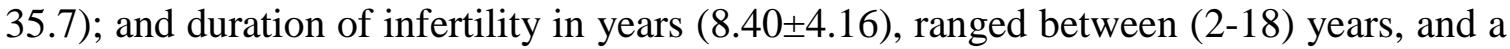
large percent of them had a history of primary subfertility $(86.7 \%)$. Regarding the cause of subfertility, a high percent of the studied groups of unexplained cause with a percentage (40\%). Regarding ICSI outcome, the pregnancy rate was $28.89 \%$. In women with unexplained cause, pregnancy rate was $(33.30 \%)$ followed by women with explained 
cause which was (25.90\%). Pregnant women had better ICSI parameters than nonpregnant one. Basal hormonal levels were within normal range, also peak $\mathrm{E}_{2}$ show normal value, but $\mathrm{E} 2$ at $\mathrm{CD} 2$ was of higher significance in an unexplained type or group. Follicular and serum AZA was higher in women with unexplained cause than in women with explained cause but of no significant difference. Furthermore, peak mean of Follicular AZA in women with unexplained infertility was (10.29 IU/L), followed by ovulatory cause. Pregnancy rate in women with high AZA decreased, and it affect ICSI outcome in general. Regarding FF -AZA, higher follicular fluid values were in unexplained cause. Also, positive non-significant correlation between E2 and follicle Finally, there were some correlations between count with serum AZA was observed. blood serum AZA, FF AZA and ICSI outcome and other parameters.

Conclusion: We conclude from this study that multiple factors affect ICSI outcome, and may be used as markers of fecundity for counseling IVF/ICSI candidates to elevate success rate and decrease the cancellation cycles. Women with unexplained subfertility must firstly be checked for presence of AZA and treated before beginning ICSI cycle to increase conception rate. Minimal immune activation as detected by serum and follicular AZA may help in success rate of ICSI outcome.

Key words: Anti-zona antibody (AZA), Explained and unexplained infertility, Follicular fluid, ICSI outcomes.

\section{Introduction:}

Infecundity means the failure of a couple to conceive or to get a live birth after 1 year or more of unprotected regular dynamic sexual intercourse for those females less than 35 years and after 6 months for females over age 35 years (1).

A successful conception was the consequence of multiple complex interactions between the receptive uterus and the mature blastocyst under immune-hormonal control $(2,3)$.

Human female ovary can be the target of an autoimmune attack in certain circumstances, liking some organ-specific or systemic autoimmune diseases. The subsequent ovarian dysfunction often clinically results in premature ovarian failure, but other pathologies involving the ovaries, such as unexplained infertility, polycystic ovary syndrome (PCOS), endometriosis, repeatedly unsuccessful IVF attempts and may be responsible for the pathophysiology of preeclampsia(PE) or spontaneous miscarriages $(4,5)$ have been associated with anti-ovarian autoimmunity (6). The targets, which comprise various steroid genic enzymes, gonadotrophins and their receptors, the corpus luteum, zona pellucid(ZP) and egg, are reviewed.

The topic of immunology of human reproduction is receiving increasing attention. Also journals of immunology are publishing more papers on every part of the immunology of reproduction (7). According to previous researches, cellular and, particularly, humoral auto immunologic perturbations are responsible for development of female infertility.

The loss of ability of the immune system to distinguish self from non-self-products is autoimmunity, which is characterized by inflammation, and cellular, antibody mediated and immune-complex-mediated processes requiring innate and adaptive immunity (8). 
Principally endocrine autoimmunity is organ specific but is often also related to polyclonal activation (9) and non-endocrine autoimmunity (10).

Also subclinical autoimmunity precedes clinical autoimmune diseases by months to years, and uniformly is related to decreased fecundity and an increased abortion risk at the subclinical stage in females (11). While the anti ZP antibodies are considered to be a cause of infertility because of their blocking effects on sperm-ZP binding (12).

The anti-zona pellucida antibodies look to be essentials autoantibodies involved in the cause of infecundity (13), particularly unexplained infecundity $(14,15)$. Those a cellular zona pellucida surrounding oocyte though ovulation happens and stays in place till the implantation, the implantation, comprises receptors (ZP1, ZP2, ZP3) (16) to sperm cells which are _ for some exceptions _ species - specific (17). The primary connection of sperm with egg is a receptor - mediated process (18).

Particular antibodies against these acidic glycoproteins have the ability to obstruct sperm connection and infiltration into egg, also might be the reason for the normal (natural) or stimulated (artificial) fertilization (19).

Intra-cytoplasmic sperm injection is "a form of micromanipulation including the injection of only one motile (live) sperm cell directly into the ooplasm of MII stage oocyte (20). ICSI successfully deals with the issue of infecundity, also gives and gives great courage for infecundable patients. The most important indications for intracytoplasmic injection consist of sever man factor, blocked tube, ovarian failure, lower ovarian reserve, endometriotic disorders and unexplained infecundity (21).

\section{Methodology:}

\section{Study Design:}

A prospective analytical cross sectional one year study had been conducted in the Fertility center in Al-Sadr Medical City in An-Najaf governorate involving those who were seeking treatment for infecundity disorders and they were treated by ICSI.

\section{Investigated patients:}

Those members $(n=45$, where $n=$ random sample size) were chosen from females who were selected from females that were present at the fertility center from October 2015 to December 2016. Wholly sub-fertile couples were evaluated to their reason for subfertility by semen examination for the men and the women were required around their medical, surgical and gynecological history. Complete physical examination and anthropometric measures such weight, height and body mass index (BMI) had been done; where is BMI defined as: weight by $\mathrm{Kg}$ divided by the square of the patient's height (22). Gynecological examination might have been done at second day of cycle, ultrasonography, hystero- salpingeo- gram and blood tests for LH, FSH, AZA, prolactin, E2, mid luteal progesterone level, TFT and seminal analysis, to categorize sub-fertile women into explained $(n=27)$ and unexplained groups $(n=18)$. Selection Criteria:1-Male partner: those who suffer from infertility with ejaculated semen who had normo- zoospermia, oligo- zoospermia, astheno- zoospermia and teratozoospermia according to (23). 2-Female partner: those who had infertility problems were included in the study. 3- Cycles of ICSI that result in aspiration of follicle and retrieval of oocyte with embryo transfer. 4- for HIV, hepatitis B and C Screening tests implicated and 


\section{Measurements:}

\section{Preparation of female for ICSI:}

Trans-vaginal (U/S): A gynecologist did trans-vaginal U/S on cycle day 2 in the center of the fertility to assess antral follicle count (AFC) using "real time ultrasound device, using "vaginal probe (5-7 MHZ)". Follicles measuring 2-10 mm were counted to assess the antral follicles, also to measure the endometrial thickness and to exclude the presence of

ovarian

cyst.

Evaluation of Serum and Follicular (AZA): Cycle day 2 serum separated utilizing a serum separator tube and permit tests to cluster to two hours toward room temperature or overnight toward 2- $8 \mathrm{C}^{0}$. Centrifuge for $3000 \mathrm{rpm}$ to 10 minutes, then eliminate serum and test immediately or aliquot and store tests at $20-80 \mathrm{C}^{\circ}$ to assess the concentration of serum AZA by using special human Elisa kit (MyBiosource/ USA).

Centrifuge those follicular fluids obtained at day of egg retrieval at $3000 \mathrm{rpm}$. for about ten min. in order to eliminate the cell fragments, also analyze immediately or stored at ( -20 or -80$) \mathrm{C}^{0}$ to assess the concentration of the follicular fluid AZA by using the same kit.

Ovarian Stimulation Protocols: Single infusion of GnRH (a, Decapeptyl; 0.1 m.g.) might have been administered s.c. during CD2 administered subcutaneously at cycle day 2 waiting for the outcomes of FSH, LH and E2.

Short Protocol $(\mathbf{n}=\mathbf{2 7})$ : From the cycle day 2, agonist had been started and it ended at the development of mature follicles until HCG administration" Gonadotropins started on CD3, so those females received $0.1 \mathrm{~m} . \mathrm{g}$./day of decapeptyle. Those standard methods to controlled ovarian hyper-stimulation might have been to start with $150 \mathrm{IU} / \mathrm{d}$ for r. FSH as gonal-f, follitropine - alfa 75 IU/ampule, these are given subcutaneously or intramuscularly. Gn. RH. agonist upheld till the HCG injection day" (24).

Long Protocol $(\mathbf{n}=3)$ : The Gn. RH agonist began in the luteal stage at CD21 of previous cycle. After that begin Gn. stimulation and remain on Gn. RH with Gn. till the follicles accomplish of good measure. Human menopausal gonadotropins might have been supplemented as stated by physician's assessment. Afterward stop agonist and FSH, also give HCG (5000 IU I.M.) (25).

Antagonist Protocol $(\mathbf{n}=\mathbf{1 5})$ : Those methods for stimulation to start with $\mathrm{r}$. FSH infusion (Gonal- f) around CD2 or CD3 of menstrual cycle. The r. FSH might have been last till HCG day. Subsequently, HMG started upon clinician's approach. Serial ultrasonography might have been accomplished for assessment for follicles development. 
Dose and Timing about HCG Administration: For normal responders, HCG may be as a rule injected at the E2 level which must be more than $400 \mathrm{pg} / \mathrm{ml}$ for 3 days and the diameter of 2 or more follicles arrived at $17 \mathrm{~mm}$ or bigger. Ovulation will be triggered by pregnyl (5000- 10000 IU) i. m, so ovulation happened in about thirty-six to fourty hours following infusion (26).

\section{Statistical Analysis:}

Statistical analysis was done by using SPSS (statistical package for social sciences) version 20(2011). In which we use mean, standard deviation, numbers and percentages as descriptive statistics. For analysis we use chi square for categorical data and independent sample t-test, analysis of variance (ANOVA) with bonferroni correction and pearson correlation coefficient for continuous variables (27).

\section{$\underline{\text { Results }}$}

1.Intra-cytoplasmic sperm injection outcomes in studied group (explained and unexplained): The mean of retrieval oocytes, and their stage, embryo grading and number of embryos and other ICSI characters of sub fertile women who undergo ICSI are edited in Table (4-2).

Table (1): Major ICSI outcomes in explained and unexplained groups.

\begin{tabular}{|l|l|l|l|}
\hline Variable & Unexplained $(\mathrm{n}=18)$ & Explained $(\mathrm{n}=27)$ & P value \\
\hline $\begin{array}{l}\text { Follicle } \\
\text { count }\end{array}$ & $\mathbf{1 3 . 4 1} \pm \mathbf{4 . 5 1}$ & $\mathbf{1 5 . 8 9} \pm \mathbf{6 . 9 9 3}$ & $\mathbf{0 . 1 9 9}$ \\
\hline $\begin{array}{l}\text { Retrieved } \\
\text { oocyte. }\end{array}$ & $\mathbf{9 . 2 3} \pm \mathbf{3 . 3 4}$ & $\mathbf{8 . 5 2} \pm \mathbf{5 . 0 1 7}$ & $\mathbf{0 . 1 9 8}$ \\
\hline Egg at M II & $\mathbf{6 . 5 8} \pm \mathbf{2 . 5}$ & $\mathbf{8 . 2} \pm \mathbf{5 . 1}$ & $\mathbf{0 . 1 5 1}$ \\
\hline $\begin{array}{l}\text { Number of } \\
\text { injected } \\
\text { oocyte }\end{array}$ & $\mathbf{6 . 8 1} \pm \mathbf{2 . 4}$ & $\mathbf{0 . 3 1 7}$ \\
\hline $\begin{array}{l}\text { 2PN } \\
\text { Fertilization } \\
\text { rate }\end{array}$ & $\mathbf{5 7 . 0 3} \pm \mathbf{2 9 . 5}$ & $\mathbf{4 . 2 3} \pm \mathbf{2 . 8 4}$ & $\mathbf{6 1 . 0 1} \pm \mathbf{2 7 . 5 5}$ \\
\hline $\begin{array}{l}\text { Number } \\
\text { Embryo }\end{array}$ & $\mathbf{3 . 7 5} \pm \mathbf{1 . 7 7}$ & $\mathbf{5 . 2} \pm \mathbf{3 . 1 4}$ & $\mathbf{0 . 6 9 3}$ \\
\hline $\begin{array}{l}\text { Cleavage } \\
\text { rate }\end{array}$ & $\mathbf{9 8 . 0 3} \pm \mathbf{2 2 . 4 2}$ & $\mathbf{9 0 . 6 8} \pm \mathbf{2 2 . 9 5}$ & $\mathbf{0 . 3 2 9}$ \\
\hline PR\% & $\mathbf{( 6 / 1 8 ) 3 3 . 3 \%}$ & $\mathbf{( 7 / 2 7 ) 2 5 . 9 \%}$ & $\mathbf{0 . 5 9 1}$ \\
\hline $\begin{array}{l}\text { Grade } \\
\text { I(embryo) }\end{array}$ & $\mathbf{2 \pm 1}$ & $\mathbf{2} \pm \mathbf{2}$ & $\mathbf{0 . 7 9 3}$ \\
\hline $\begin{array}{l}\text { Grade } \\
\text { II(embryo) }\end{array}$ & $\mathbf{2 . 1 5} \pm \mathbf{1}$ & $\mathbf{3 . 3 8} \pm \mathbf{2 . 5 7}$ & $\mathbf{0 . 1 1 2}$ \\
\hline
\end{tabular}




\begin{tabular}{|l|l|l|l|}
\hline $\begin{array}{l}\text { Endometrial } \\
\text { thickness } \\
(\mathrm{mm})\end{array}$ & $\mathbf{9 . 2 2} \pm \mathbf{2 . 5 1}$ & $\mathbf{1 0 . 1 5} \pm \mathbf{2 . 9}$ & $\mathbf{0 . 2 7 6}$ \\
\hline
\end{tabular}

Independent sample t-test

There is no significant difference in all variables related to ICSI outcomes between explained and unexplained group of infertility.

\section{Pregnancy rate in studied group:}

A total of 45 women with subfertility had been included in the study. The ICSI outcome of these women was $28.89 \%$ success and $71.11 \%$ failure as shown in figure 1 .

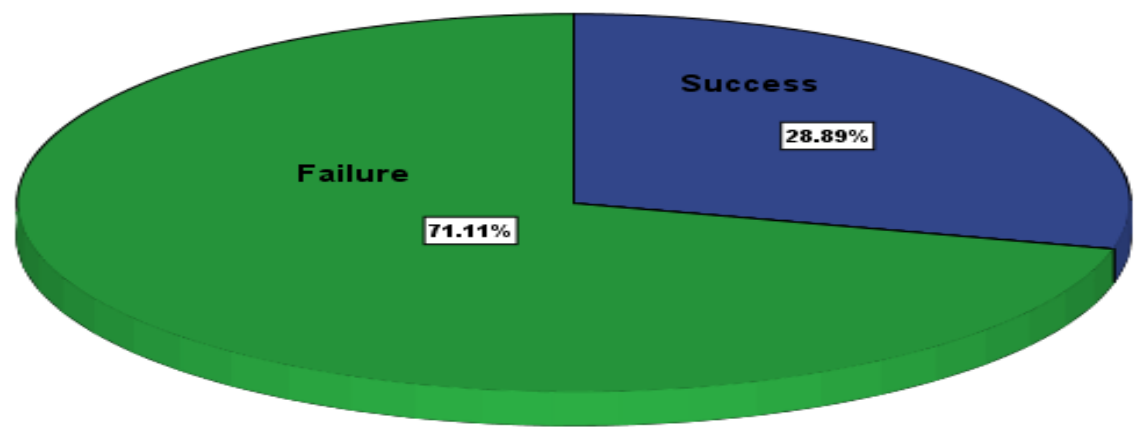

Figure (1): Pie chart show Pregnancy rate (Success Rate) in studied group.

The pregnancy rate according to the cause of subfertility was described in figure (2) in which higher pregnancy rate shown among unexplained group, followed by explained group.

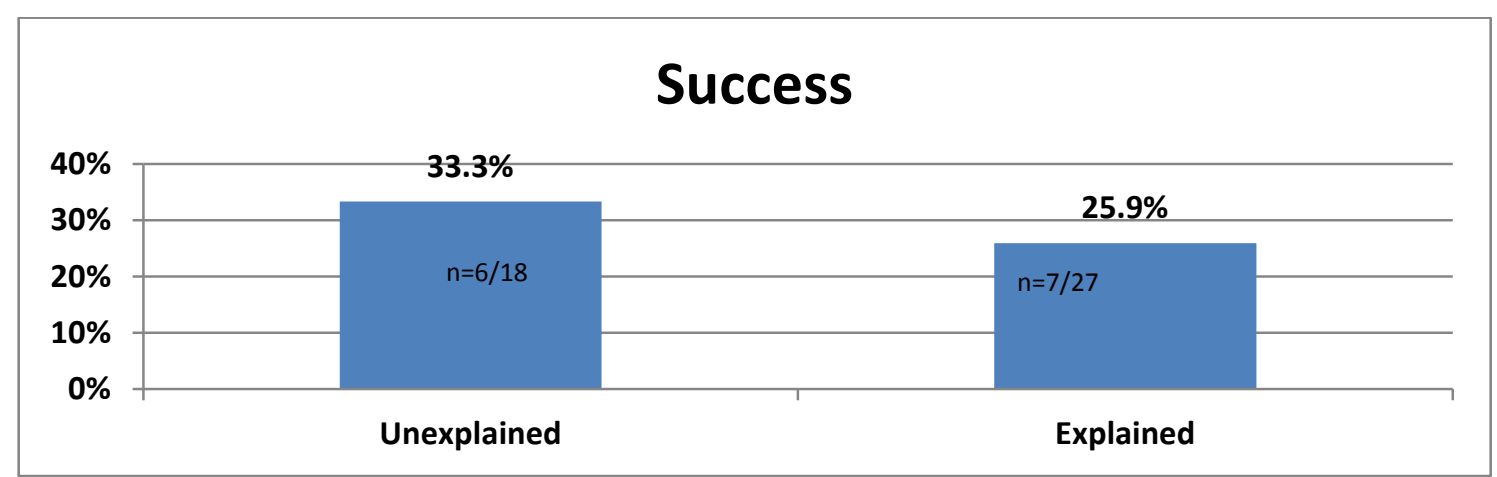


Figure (2): Show pregnancy rate (success rate) in different studied group.

3. Comparison between explained and unexplained group in AZA concentration in follicular fluid and serum of studied sub-fertile women:

The mean of follicular (at day of oocyte retrieval) and serum AZA (at CD2) concentrations in explained and unexplained cause of studied sub-fertile women.

Table (3): Comparison between explained and unexplained cause of infertility in AZA concentration in follicular fluid and serum of studied women.

\begin{tabular}{|l|l|l|l|}
\hline AZA & Unexplained(n=18) & Explained $(\mathrm{n}=27)$ & P value \\
\hline $\begin{array}{l}\text { FF } \\
\text { concentration } \\
\text { (ng./ml) at } \\
\text { oocyte } \\
\text { retrieval }\end{array}$ & $\mathbf{1 3 3 . 3 8} \pm \mathbf{4 9 . 0 4}$ & $\mathbf{1 1 2 . 4 8} \pm \mathbf{3 2 . 4 3 6}$ & $\mathbf{0 . 0 9 2}$ \\
\hline $\begin{array}{l}\text { Serum } \\
\text { concentration } \\
\text { (ng./ml) at } \\
\text { CD2 }\end{array}$ & $\mathbf{9 0 . 8 5} \pm \mathbf{2 5 . 8 8 *}$ & $\mathbf{8 8 . 9 8} \pm \mathbf{3 2 . 0 3}$ & $\mathbf{0 . 8 4 0}$ \\
\hline
\end{tabular}

Independent sample t-test

In spite of higher concentration of AZA in serum and follicular fluid in an unexplained group of sub-fertile women but it is not significant as shown in table 3

4.Correlation relations between follicular AZA concentrations and ICSI outcomes:

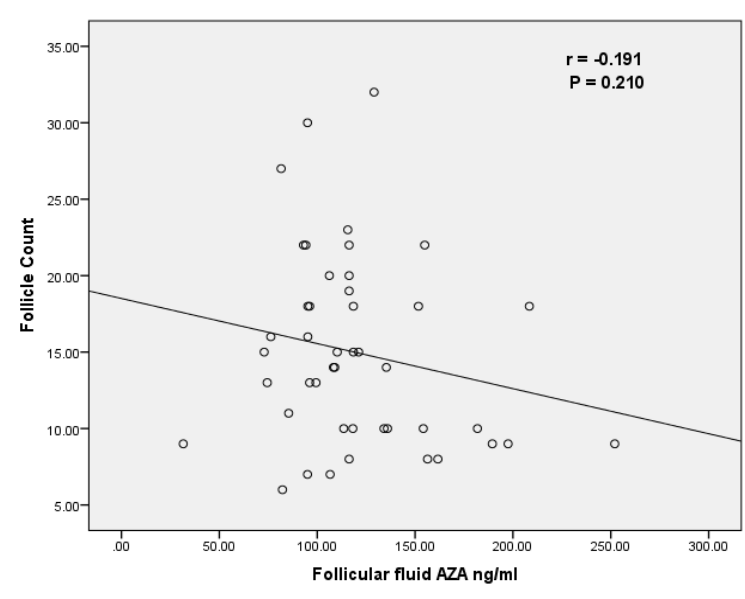

Figure (4.1): Correlation between follicular fluid AZA and follicle count. There is no significant correlation between follicular fluid AZA and follicle count but negative relation. 


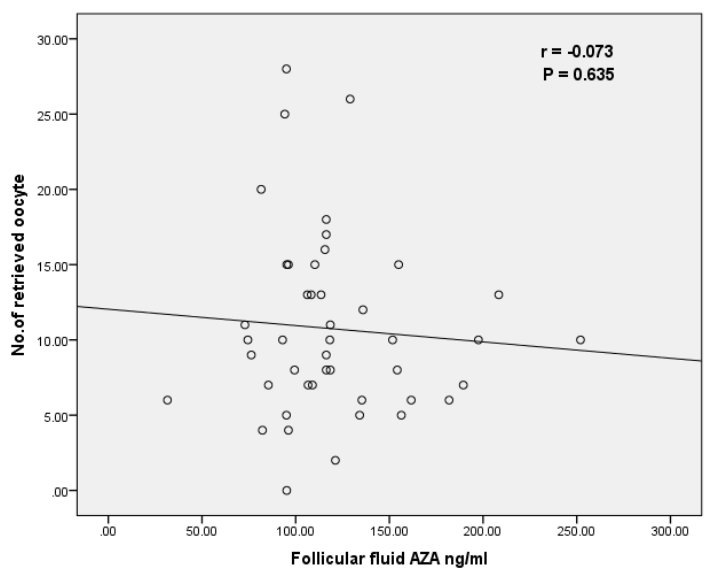

Figure (4.2): Correlation between follicular fluid AZA and number of retrieved oocyte.

There is no significant correlation between follicular fluid AZA and number of retrieved oocyte.

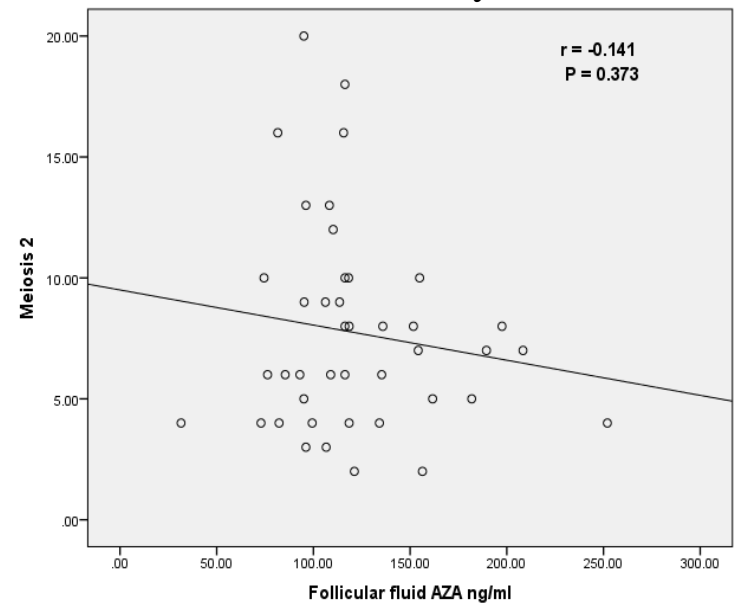

Figure (4.3): Correlation between follicular fluid AZA and M II egg stage. There is no significant correlation between follicular fluid AZA and MII.

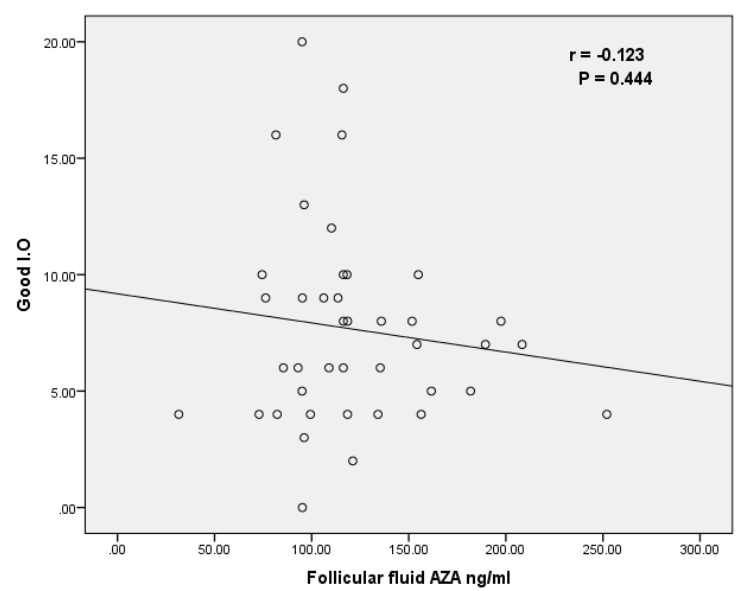

Figure (4.4): Correlation between follicular fluid AZA and no. of I.O.

There is no significant correlation between follicular fluid AZA and no. of Injected oocytes.

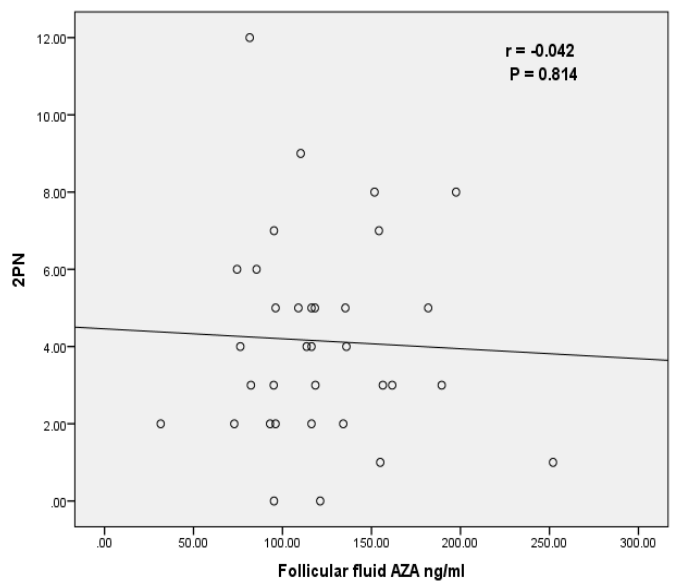

Figure (4.5): Correlation between follicular fluid AZA and no. of 2PN. There is no significant correlation between follicular fluid AZA and 2PN number. 


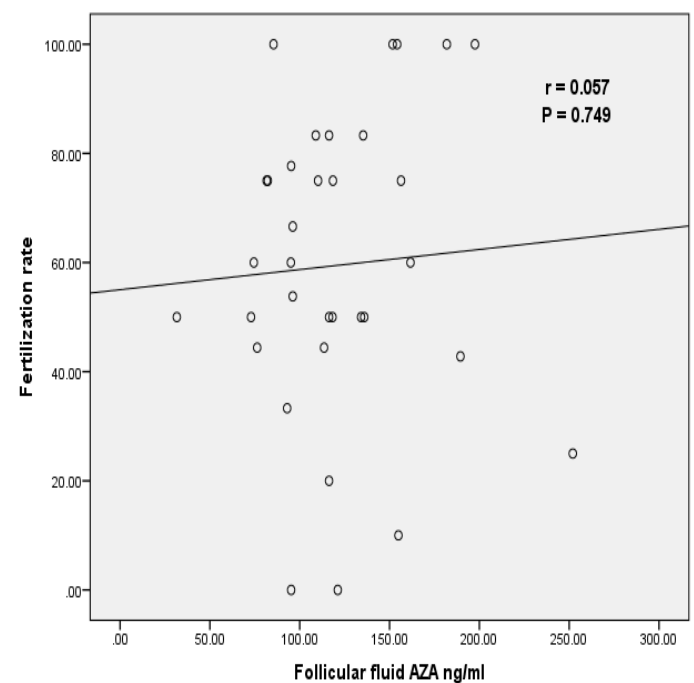

Figure (4.6): Correlation between follicular fluid AZA and fertilization rate.

There is no significant correlation between follicular fluid AZA and fertilization rate but positive relation.

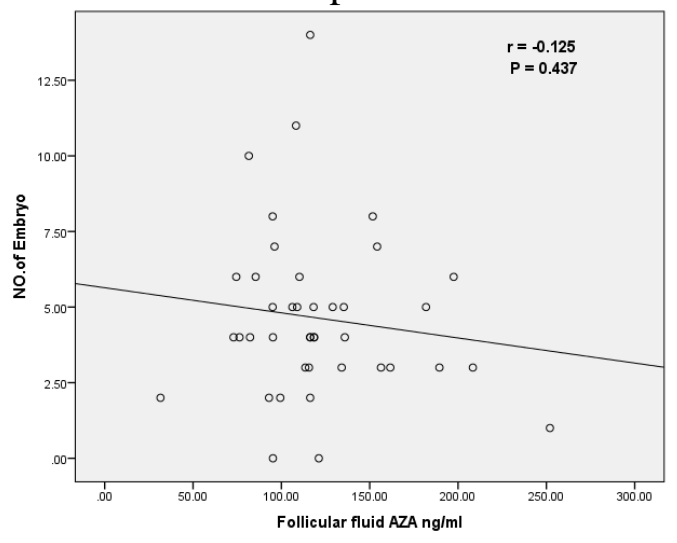

Figure (4.7): Correlation between follicular fluid AZA and number of embryos.

There is no significant correlation between follicular fluid AZA and number of embryos.

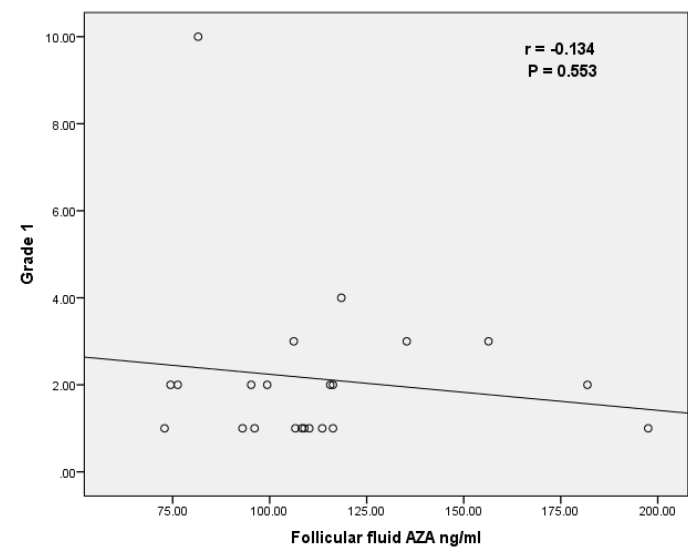

Figure (4.8): Correlation between follicular fluid AZA and Grade I embryo.

There is no significant correlation between follicular fluid AZA and grade 1 .

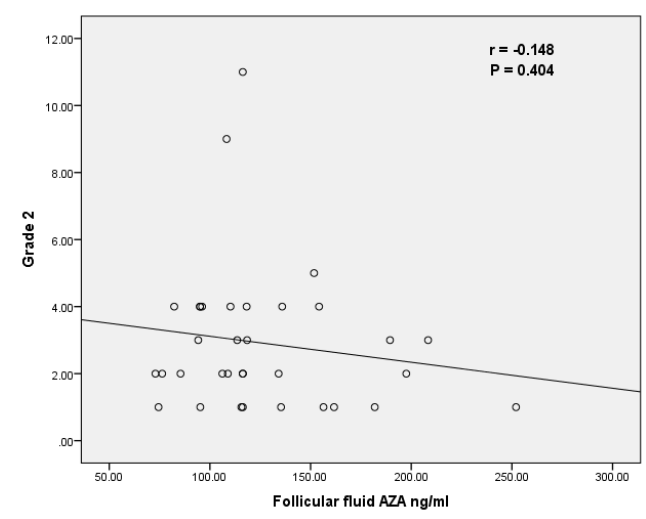

Figure (4.9): Correlation between follicular fluid AZA and Grade II. There is no significant correlation between follicular fluid AZA and Grade II. 


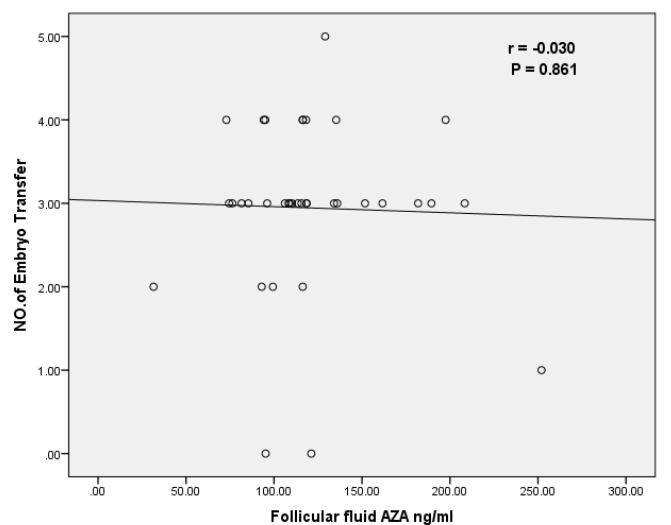

Figure (4.10): Correlation between follicular fluid AZA and number of embryos transferred.

There is no significant correlation between follicular fluid AZA and number of embryos transferred.

5. Correlation relations between serum AZA concentrations and ICSI outcomes:

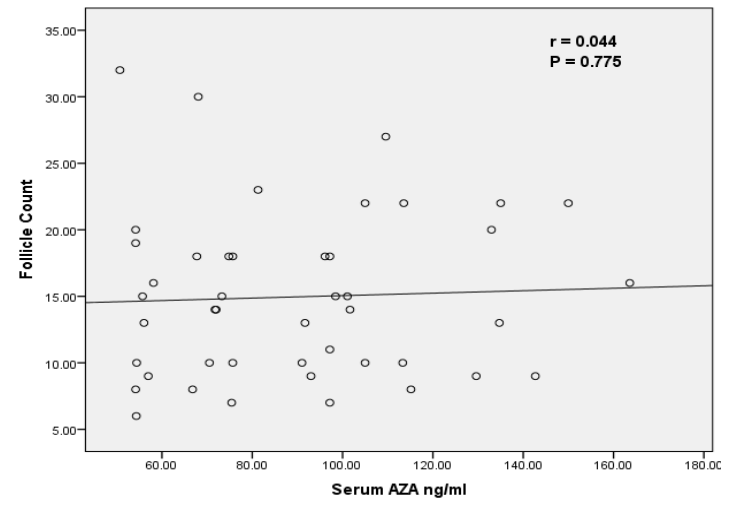

Figure (5.1): Correlation between serum AZA and follicle count.

There is no significant correlation between serum AZA and follicle count.

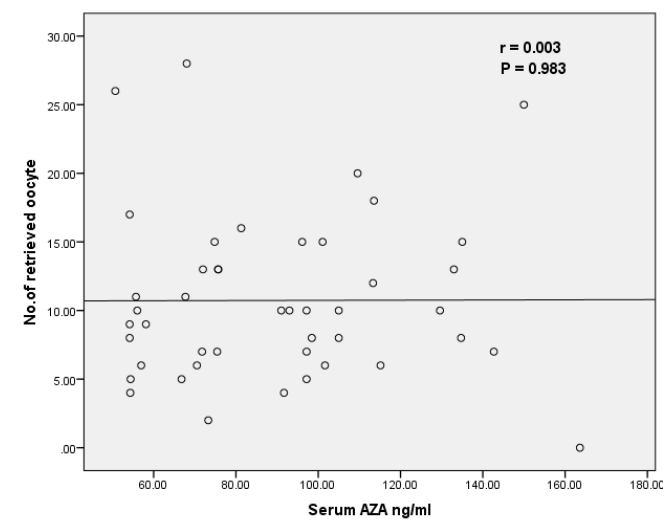

Figure (5.2): Correlation between serum AZA and number of retrieved oocyte number.

There is no significant correlation between serum AZA and number of retrieved oocyte number.

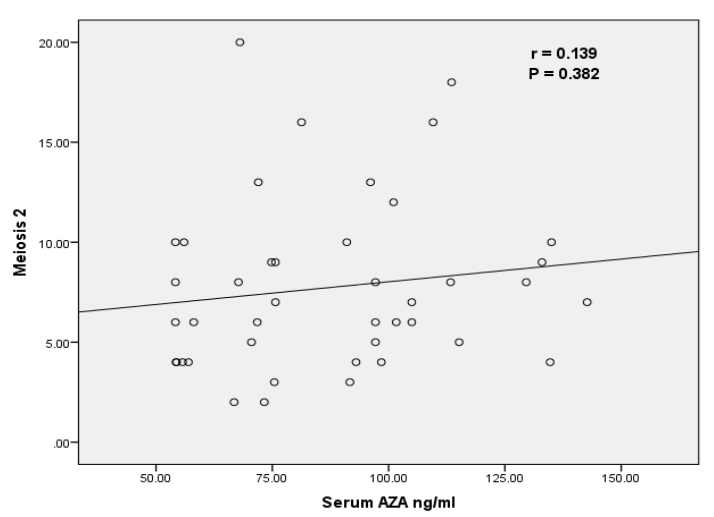

Figure (5.3): Correlation between serum AZA and number of MII egg.

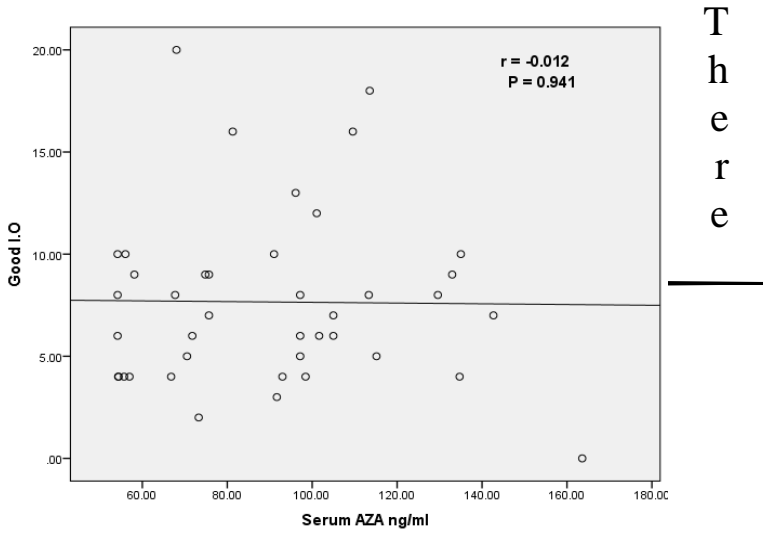


is no significant correlation between serum AZA and no. of MII.

Figure (5.4): Correlation between serum AZA and no. of I.O.

There is no significant correlation between serum AZA and no. of I.O.

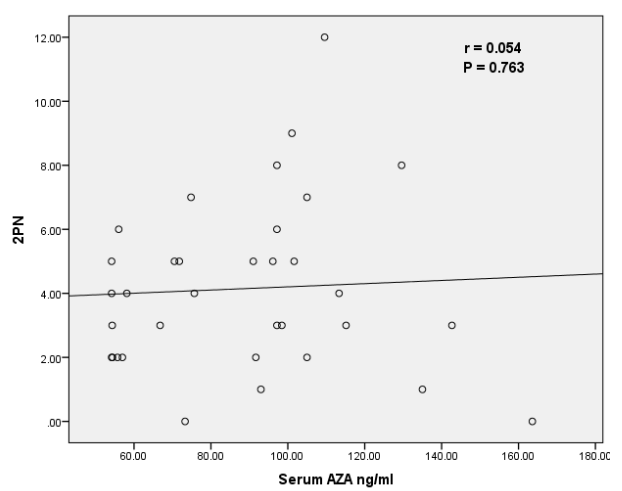

Figure (5.5): Correlation between serum AZA and 2PN no.
There is no significant correlation between serum AZA and 2PN no.

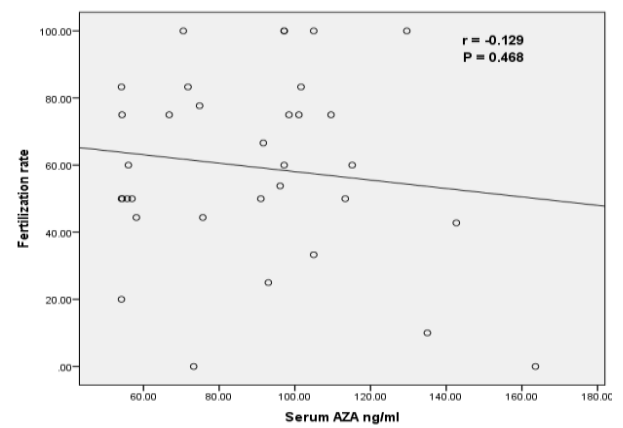

Figure (5.6): Correlation between serum AZA and fertilization rate.

There is no significant correlation between serum AZA and fertilization rate but negative relation.

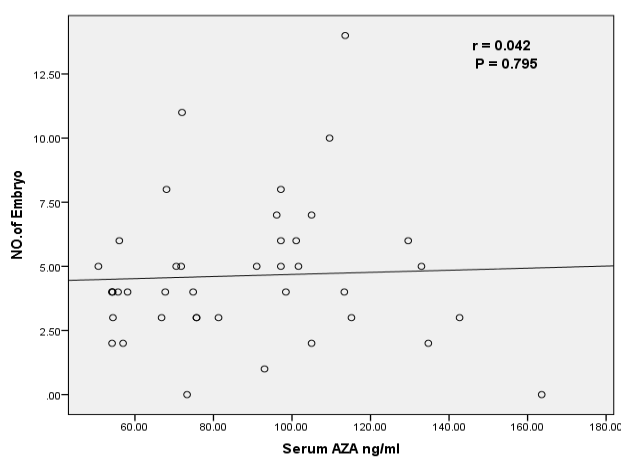

Figure (5.7): Correlation between serum AZA and number of embryos. There is no significant correlation between serum AZA and number of embryos.

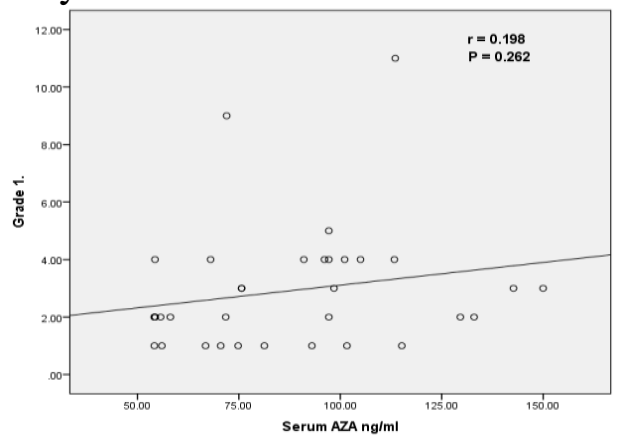

Figure (5.8): Correlation between serum AZA and no. of grade $I$. 
There is no significant correlation between serum AZA and no. of grade I.

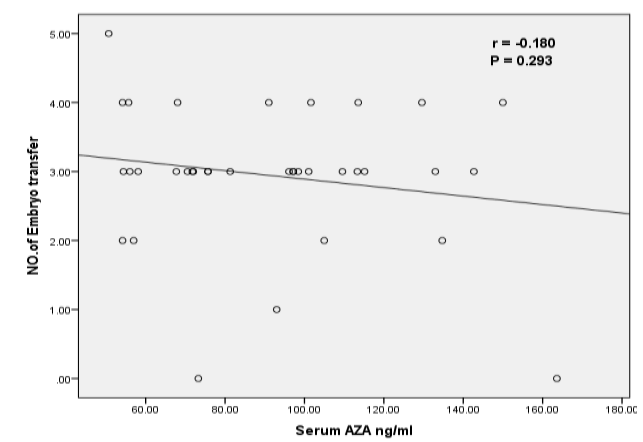

Figure (5.9): Correlation between serum AZA and number of embryo transferred.

There is no significant correlation between serum AZA and number of embryo transferred.

6. The correlation of $A Z A$ concentrations in follicular fluid and serum in both explained and unexplained groups of studied sub-fertile women:

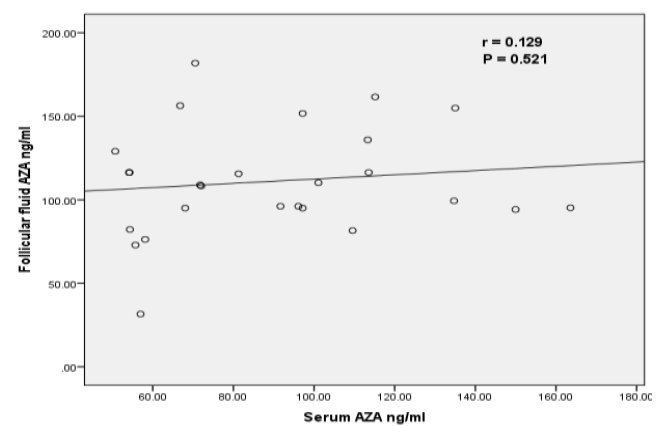

Figure (6.1): Correlation between follicular fluid and serum AZA in explained group.

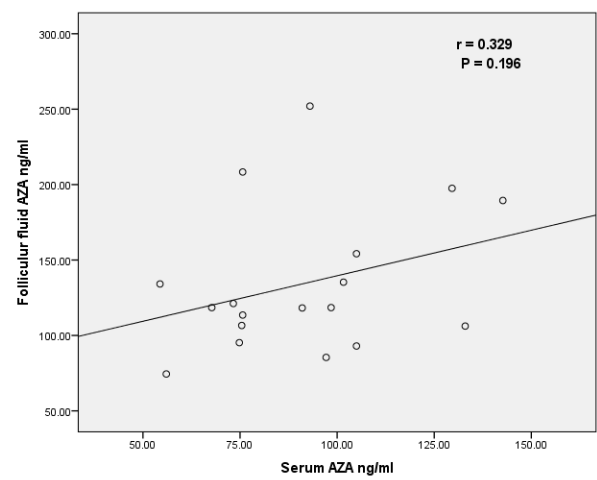

Figure (6.2): Correlation between follicular fluid and serum AZA in unexplained group.

The correlation of AZA in follicular fluid and serum shows positive but nonsignificant correlation in both explained and unexplained groups as shown in figure $(6.1 ; 6.2)$.

\section{$\underline{\text { Discussion }}$}

Statistically, the AZA concentrations obtained from both follicular fluid and serum for females with explained and unexplained infecundity in our study were of no significant biologic component. But in these groups, the concentrations obtained from unexplained one were slightly higher than in other one (133.38 vs. $112.48 ; 90.85$ vs $88.98 \mathrm{ng} / \mathrm{ml}$ ) respectively. However, the significantly raised concentrations of AZA in follicular fluid and serum of females with unexplained infecundity than in the explained females (133.38, 90.85 vs. $112.48,88.98 \mathrm{ng} / \mathrm{ml}, P 0.092,0.840$ ) appears to be worth noticing.

Depending on the obtained results, antizona antibodies is more related to (unexplained) than (explained) infecundity. These suggestive results contradicts the theory by Gleicher et al. (28), who discovered a comparable immunizer profile for females with unexplained infecundity in addition to endometriotic females, where they 
suggested that the reason of limitation in conceptive potential of $1^{\text {ist }}$ group may be due to subtle and endometriotic foci with microscopy.

Correlation analysis of serum and follicular fluid AZA in the explained and unexplained groups of sub-fertile women viewed a positive without statistical significant difference (statistically not significant at $P=0.521, r=0.129 ; P=0.196, r=0.329$ ).

The comparison between reports data and our outcomes is more difficult due to ales reports have considered with AZA presence in both compartments (serum and follicular fluid) in females with explained and unexplained types. Similar results, by using different techniques have obtained, by some other investigators. Czuppon et al. (29) and El- Roeiy et al. (30), utilizing the qualitative immune- test and egg cells of porcine , explained a more frequent appearance of serum AZA in an infecundable females than in normal reproductive controls, also Singh \& Mhaskar (31) proved this propensity .

Our study found that higher follicular fluid and serum AZA concentrations in females with unexplained than in explained infecundity. Hovav et al., (18) used an available commercial ELISA kit and distinguished these AZA anti-zona in the serum specimens for thirty-three percent of females who didn't respond to stimulation of the ovaries with hormones prior to planned in vitro fertilization.

In an unexplained group of females, the pregnancy rate was $(33.30 \%)$, and in a group of patients with explained type was $(25.90 \%)$. This result consolidated the result that obtained by (32) who stated that pregnancy success rates for IVF procedures with ICSI have been shown in some studies to be higher than for IVF without ICSI.

This is because of many of the cases needing ICSI, the woman is relatively young and fertile (good egg quantity and quality) as compared to some of the women having IVF for other reasons.

In our study we assessed the higher concentrations of AZA in FF and sera of infertile women with unexplained type than in patients with explained type in relation to ICSI outcomes and pregnancy rates.

Additionally, there were no significant connection between appearance of AZA and no. of oocytes, embryos, FR and clinical PR. But their pregnancy rates were only $30 \%-45 \%(33,34,35)$, which mimic pregnancy rate in our center $(28.89 \%)$. Also the pregnancy rate by orvieto et al. was $31.25 \%(36,37)$, and (38) pregnancy rate was $42.9 \%$.

\section{CONCLUSION:}

We concluded that the high frequency of antizona pellucida antibodies and long time failure of response to medications in females with unexplained infecundity, proposes a causative connection of Ab's with infecundity which might nearly associated with reduction of sperm_oocyte interaction by those auto antibodies, generated in these females. By conclusion, the appearance of these Ab's, might have side impacts on the results of ART.

Intra-cytoplasmic Sperm Injection is a more which keeps them away from the expected destructive impacts of anti zona antibodies on the no. of eggs, embryos, fertilization and pregnancy rates.

\section{Recommendations:}

1 -We recommend the entrance of autoantibodies test within the tests used in our ICSI center before starting management especially in women with unexplained infertility.

2-We should take larger sample size to avoid errors and getting better results.

\section{References}


1-Wasiu Eniola O., Adebayo Adetola A. and Taiwo Abayomi B., 2012. A review of female infertility: important etiological factors and management. J Microbiol Biotech Res, 2(3): 379385 .

2-Saito S., 2000. " Cytokine network at the fetomaternal interface," Journal of Reproductive Immunology, vol. 47, no. 2, pp. 87-103.

3-Thellin O., Coumans B., Zorzi W., Igout A. and Heinen E., 2000. " Tolerance to the foeto- placental 'graft': ten ways to support a child for nine months," Current Opinion in Immunology, vol.12, no. 6, pp. 731-737.

4-Reimand K., Talja I., Metsküla K., Kadastik Ü., Matt K. and Uibo R., 2001. Autoantibody studies of female patients with reproductive failure. Journal of Reproductive Immunology. 51(2): 167-176.

5-Forges T., Barbarino- Monnier P., Faure G.C., and B'en'e M. C., 2004. "Autoimmunity and antigenic targets in ovarian pathology," Human Reproduction Update, vol. 10, no. 2, pp. 163-175.

6-Luborsky J., 2002. "Ovarian autoimmune disease and ovarian autoantibodies," Journal of Women's Health and Gender-Based Medicine, vol. 11, no. 7, pp. 585-599.

7-Raivo Uibo,1, 2 Andres Salumets,2, 3 and Gilbert Faure, 2012. Immunological Aspects of Human Reproduction.

8-Cho J. H. \& Gregersen P. K., 2011. Genomics and the multi factorial nature of human autoimmune disease. N. Engl. J. Med. 365, 1612-1623.

9-Jasani B. et al., 1999. Natural antibody status in patients with Hashimoto's thyroiditis. J. Clin. Lab. Immunol. 51, 9-20.

10-Tagoe C. E., Zezon A. and Khattri S., 2012. Rheumatic manifestations of autoimmune thyroid disease: the other autoimmune disease. $J$. Rheumatol.39, 1125-1129.

11-Gleicher N., 1999. Reproductive failure prior to the onset of clinical autoimmune disease. Rheumatology (Oxford) 38, 485-487.

12-Takamizawa S., Shibahara H., Shibayama T., Suzuki M., 2007. Detection of antizona pellucida antibodies in the sera from premature ovarian failure patients by a highly specific test. Fertil. Steril. 88, 925-932.
13-Nishimoto T., Mori T., Yamada I. and Nishimura T., 1980. Auto antibodies to zona pellucida in infertile and aged women. Fertil Steril., Dec; 34(6):5526.

14-Shivers CA. and Dunbar BS., 1977. Autoantibodies to the Zona pellucida: A possible cause for infertility in women. Science; 197:10821086.

15-Ulcova- Gallova Z., Babcova K., Novakova P., Micanova Z., Rokyta Z. , 2004. Anti-zonal antibodies in ovulatory cervical mucus and in serum of patients with fertility disorders, Ceska Gynekol., May; 69(3): 215-8.

16-Kamada M., Daitoh T., Mori K., Maeda N., Hirano K., Irahara M., Aono T. and Mori T., 1992. Etiological implication of auto antibodies to zona pellucida in human female infertility. Am $J$ Reprod Immunol, Sep; 28(2):104-9.

17-Luborsky J., Llanes B., Davies S., Binor Z., Radwanska E.,and Pong R., 1999. “ Ovarian autoimmunity: greater frequency of autoantibodies in premature menopause and unexplained infertility than in the general population," Clinical Immunology, vol. 90, no. 3, pp.368-374.

18-Hovav Y., Almagor M., Benbenishti D., Margalioth EJ., Kafka I., Yaffe H., 1994. Immunity to zona pellucida in women with low response to ovarian stimulation, in unexplained infertility and after multiple IVF attempts. Hum Reprod, Apr;9(4):643-5.

19-Dunbar BS., Avery S., Lee V., Prasad S., Schwahn D., Schwoebel E., Skinner S., Wilkins B., 1994. The mammalian zona pellucida: its biochemistry, immunochemistry, molecular biology, and developmental expression. Reprod. Fertil Dev.; 6(3):331-47.

20-De Vos A., 2000. Intra-cytoplasmic sperm injection (ICSI). Hum Reprod, 15(4): 59-64.

21-Huang JYJ. and Rosenwaks Z., 2012. In vitro fertilization treatment and factors affecting success. Best Pract Res Clinical Obestet and Gynecol, 26: 777-788.

22-WHO Expert Consultation., 2004. Appropriate body-mass index for Asian populations and its implications for policy and intervention strategies. The Lancet, 363(9403): 157-163. 
23-Badawy A., Wageah A., El Gharib M. and Osman EE., 2011. Prediction and diagnosis of poor ovarian response: The dilemma. J Reprod Infertil, 12(4): 241-248.

24-Elder K. and Dale B., 2011. Micromanipulation techniques In: Text book of In-Vitro Fertilization. This $\mathbf{3}^{\text {rd }}$ edition published by Cambridge University Press, Ch.13, P.2116.

25-Elder K. and Dale B., 2011. Endocrine control of reproduction -Controlled ovarian hyperstimulation for ART. In: In-Vitro Fertilization. $3^{\text {rd }}$ edition. Elder K and Dale B. (eds.), Cambridge: 1926.

26-Al-Taee H., Al-Khfaji Z. and Al-Madfai Z., 2014. The Role of Ovarian Reserve Tests in predicting Intra-Cytoplasmic Sperm Injection Cycles Outcome. Asian J of Pharma, Nurs and Med Sci, 2(1): 15-23.

27-Daniel WW., 1999. Probability and distribution biostatistics. In: A foundation for analysis in health science. 7th edition. Daniel WW. (ed.), John willey and Sons, INC-USA: 83-123.

28-Gleicher N., El-Roeiy A., Confino E., and Friberg J., 1989. "Reproductive failure because of auto antibodies: unexplained infertility and pregnancy wastage," American Journal of Obstetrics and Gynecology, vol. 160, no. 6, pp. 1376-1380.

29-Czuppon AB., Dietl J. and Tripatzis I., 1987. Solid-phase antigen immunoassay for the detection of anti-zona pellucida antibodies in clinically defined sera. J Clin Chem Clin Biochem; 25:87-90.

30- El-Roeiy A., Gleicher N., Friberg J., Confino E. and Dudkiewicz A.,1987. Correlation between peripheral blood and follicular fluid autoantibodies and impact on in vitro fertilization. Obstet Gynecol; 70:163-170.

31- Singh J., Mhaskar AM., 1985. Enzyme-linked immune sorbent determination of auto antibodies to zona pellucid as a possible cause of infertility in women. J Immunol Methods;79: 133- 141.

32- Farquhar C.; Rishworth J. R.; Brown J.; Nelen W. L. M.; Marjoribanks J., 2013. Brown, Julie, ed. "Assisted reproductive technology: an overview of Cochrane Reviews".

33- Stolwijk AM., Wetzels AM. and Braat DD., 2000. Cumulative probability of achieving an ongoing pregnancy after in-vitro fertilization and intra-cytoplasmic sperm injection according to a woman's age, subfertility diagnosis and primary or secondary subfertility. Hum Reprod;15: 203-9.

34- Check ML., Yuan W., Check JH., Swenson K., Lee G. and Choe JK., 2002. Cumulative probability of pregnancy following IVF with ICSI and fresh or frozen embryo transfer. Arch Androl.; 48:5-7.

35- Olivius K., Friden B., Lundin K. and Bergh C., 2002. Cumulative probability of live birth after three in vitro fertilization /intra-cytoplasmic sperm injection cycles. Fertil Steril;77: 505-10.

36-Orvieto R., Chen R., Ashkenazi J., BenHarush A., Bar J. and Fisch B., 2004a. Creactive protein levels in patients undergoing controlled ovarian hyper-stimulation for IVF cycle. Hum Reprod; 19:357-9.

37-Orvieto R., 2004b. Controlled ovarian hyperstimulation-an inflammatory state. J Soc Gynecol Investig 11,424-426.

38- Arefi S., Babashamsi M., Panahi P.S., Saruiy L.A. and Zeraati H., 2010. C-reactive protein level and pregnancy rate in patients undergoing IVF/ICSI. Iranian Journal of Reproductive Medicine Vol.8. No.4. pp: 197-202. 


\section{تاثير الاجسام المضاده لقثرة البيضه الخارجيه على نتائج الحقن المجهري في}

\section{المجاميع المبرره وغير المبرره}

\section{د.صبا صبيح حسين العبودي د.صاحب يحيى المرشدي د.باسمة شمخي الغزالي}

وشملت هذه الاراسة الفوقية المحتملة ه؛ امرأة دون الخصبة تنقسم إلى مجموعات فرعية؛ التي هي مجموعات المبررة

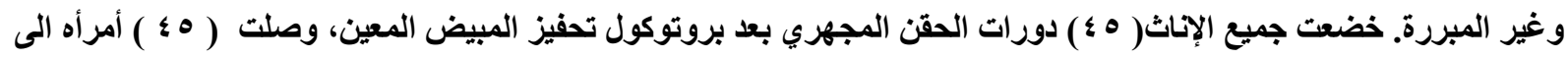

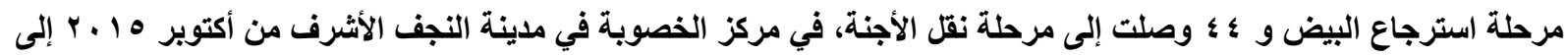

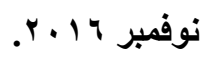

وقد خضعت النساء لتقييمات شاملة (التاريخ السريري والفصص الكامل) والتصوير بالموجات فوق الصوتية المتكرر مع

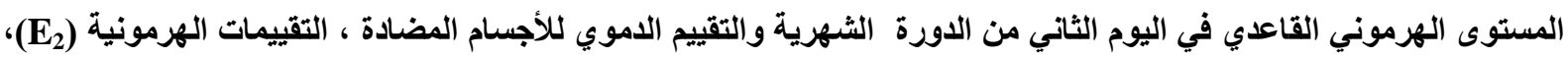

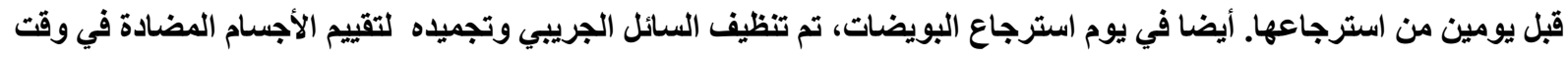
لاحق. بعد أسبوعين، تم تقييم مصل الدم ل(B-HCG ) للكثف عن الحمل البيو كيميائي.

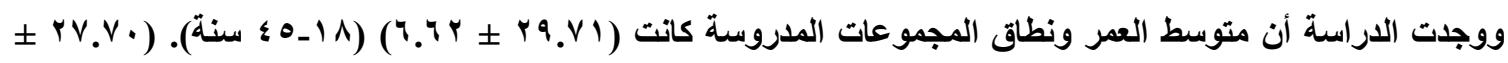

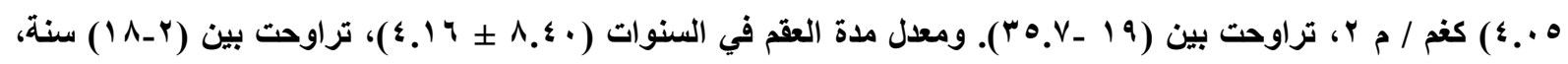

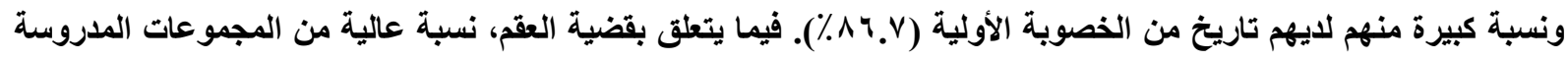

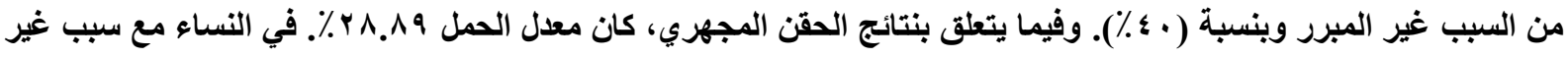

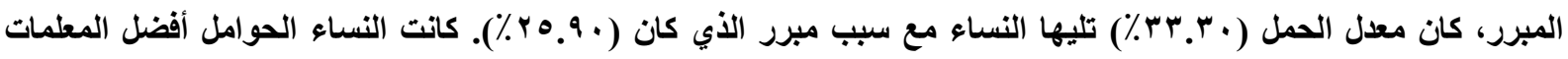

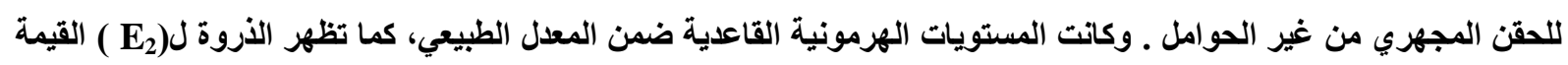


الطبيعية ايضا، ولكن ED2 كان ذات أهمية أعلى في نوع غير المبرر أو المجموعة. كان تركيز الأجسام المضادة في المصل و السائل الجريبي أعلى في النساء مع سبب غير مبرر من النساء مع سبب مبرر ولكن من أي فرق كبير. وعلاوة على ذللك، كان

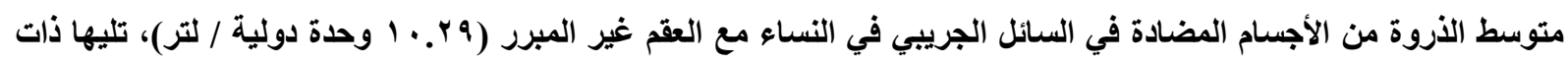

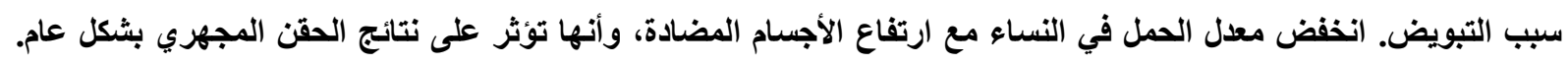

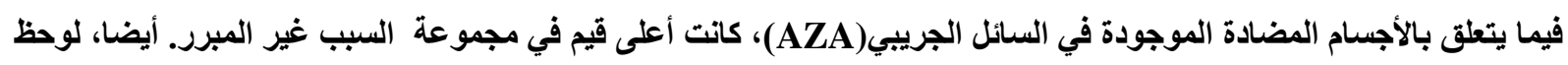

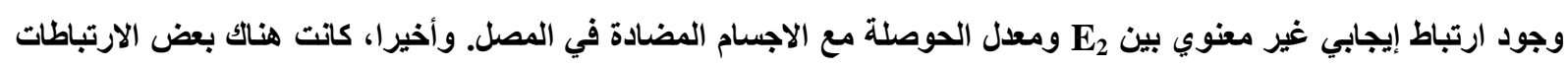

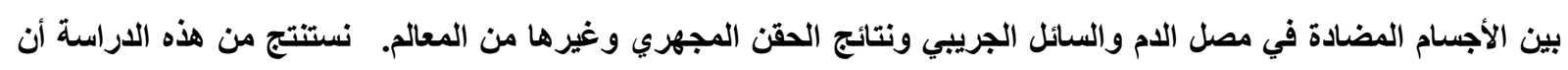

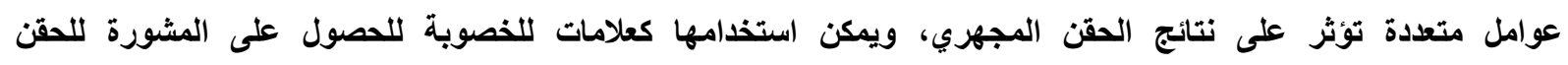

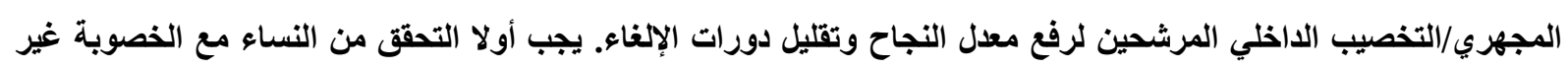

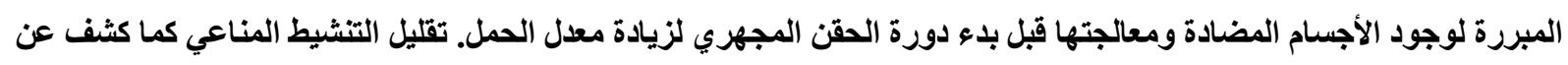
طريق الأجسام المضادة في المصل والسائل الجريبي قد يساعد في معدل نجاح نتائج الحقن المجهري. 